\title{
Development of a nomogram for predicting the presence of combined pulmonary fibrosis and emphysema
}

Xueting Yuan ${ }^{1}$, Jin Jin $^{2}$ and Xiaomao $\mathrm{Xu}^{1,2^{*}}$

\begin{abstract}
Background: In the clinical management of patients with combined pulmonary fibrosis and emphysema (CPFE), early recognition and appropriate treatment is essential. This study was designed to develop an accurate prognostic nomogram model to predict the presence of CPFE.

Methods: We retrospectively enrolled 85 patients with CPFE and 128 patients with idiopathic pulmonary fibrosis (IPF) between January 2015 and January 2020. Clinical characteristics were compared between groups. A multivariable logistic regression analysis was performed to identify risk factors for CPFE. Then, and a nomogram to predict the presence of CPFE was constructed for clinical use. Concordance index (C-index), area under the receiver operating characteristic curve (AUC), and calibration plot was used to evaluate the efficiency of the nomogram.
\end{abstract}

Results: Compared to the IPF group, the proportion of patients with male, smoking and allergies were significantly higher in the CPFE group. In terms of pulmonary function tests, patients with CPFE had lower FEV1/FVC\%, DLCONA\% pred, and higher RV, RV\%pred, VC, VC\%pred, TLC\%pred, VA, TLC, TLC\%pred, FVC, FVC\%pred and FEV1 with significant difference than the other group. Positive correlation was found between DLCO and VA\%, RV\%, TLC\% in patients with IPF but not in patients with CPFE. By multivariate analysis, male, smoking, allergies, FEV1/FVC\% and DLCO/NA\%pred were identified as independent predictors of the presence of CPFE. The nomogram was then developed using these five variables. After 1000 internal validations of bootstrap resampling, the C-index of the nomogram was $0.863(95 \% \mathrm{Cl}$ 0.795-0.931) and the AUC was 0.839 ( $95 \% \mathrm{Cl} 0.764-0.913$ ). Moreover, the calibration plot showed good concordance of incidence of CPFE between nomogram prediction and actual observation (Hosmer-Lemeshow test: $P=0.307$ ).

Conclusions: Patients of CPFE have a characteristic lung function profile including relatively preserved lung volumes and ventilating function, contrasting with a disproportionate reduction of carbon monoxide transfer. By incorporating clinical risk factors, we created a nomogram to predict the presence of CPFE, which may serve as a potential tool to guide personalized treatment.

Keywords: CPFE, IPF, Nomogram, Risk factors, Multivariable logistic regression analysis

*Correspondence: xuxiaomaobjyy@163.com

1 The Key Laboratory of Geriatrics, Beijing Institute of Geriatrics, Beijing Hospital, National Center of Gerontology, National Health Commission, Institute of Geriatric Medicine, Chinese Academy of Medical Sciences, No. 1 DaHua Road, Dong Dan, Beijing 100730, People's Republic of China Full list of author information is available at the end of the article

\begin{abstract}
Background
Pulmonary interstitial fibrosis and emphysema have long been perceived as two separate diseases. Interstitial lung diseases (ILD) encompass a large and heterogeneous group of diffuse parenchymal lung disorders characterized by distinct forms and severity of inflammation and fibrosis in alveolar walls and cavities [1]. Idiopathic
\end{abstract}

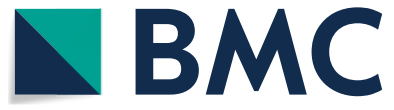

(c) The Author(s) 2021. Open Access This article is licensed under a Creative Commons Attribution 4.0 International License, which permits use, sharing, adaptation, distribution and reproduction in any medium or format, as long as you give appropriate credit to the original author(s) and the source, provide a link to the Creative Commons licence, and indicate if changes were made. The images or other third party material in this article are included in the article's Creative Commons licence, unless indicated otherwise in a credit line to the material. If material is not included in the article's Creative Commons licence and your intended use is not permitted by statutory regulation or exceeds the permitted use, you will need to obtain permission directly from the copyright holder. To view a copy of this licence, visit http://creativecommons.org/licenses/by/4.0/. The Creative Commons Public Domain Dedication waiver (http://creativeco $\mathrm{mmons}$.org/publicdomain/zero/1.0/) applies to the data made available in this article, unless otherwise stated in a credit line to the data. 
pulmonary fibrosis (IPF), an ILD of unknown cause is invariably progressive and associated with poor prognosis [2]. Emphysema, most often caused by long-term exposure to cigarette smoke, featured with abnormal and permanent enlargement of air spaces distal to the terminal bronchioles, is one of the major pathobiological processes leading to chronic obstructive pulmonary disease [3]. Progressive inflammation damages the airway mucosal epithelium, which in turn leads to airflow limitation and lung parenchymal destruction [4]. Therefore, emphysema and fibrosis are often considered distinct entities with unique pathophysiologic manifestations, but in the past 15 years, there has been an increasing recognition that these two processes may coexist in individual patients. "Combined pulmonary fibrosis and emphysema (CPFE)" was first described as a well-defined syndrome by Cottin et al. in 2005 [5].

Patients with CPFE are characterized by a relatively normal lung function due to the counterbalancing effects of fibrotic (restrictive factor) and emphysematous (obstructive factor) components [6, 7], which often lead to underestimating the severity of CPFE, or even a delayed or missed clinical diagnosis. A previous study conducted by Mejía $\mathrm{M}$ et al. reported that in the series of the 110 patients initially diagnosed with IPF, $28 \%$ were reevaluated and classified as CPFE [8]. The other study found that CPFE was found in $33.5 \%$ of 660 patients with usual interstitial pneumonia (UIP) [9]. Although computed tomography (CT) scan of the chest is routinely performed in patients with IPF, the development of emphysema is considered as a long cumulative process, which gas exchange and mechanical abnormalities may predate radiographic low attenuation areas of the lung parenchyma. Consequently, the presence of CPFE in patients diagnosed with IPF is of concern. In addition, CPFE is frequently complicated by pulmonary hypertension [10], lung cancer [11], acute exacerbations [12], and leading to poor natural history and prognosis [13]. Currently, there is still a lack of specific drugs for clinical treatment [14]. Considering this, a predictive model with reliable efficacy is of great importance to helps us raise the profile of patients with possible CPFE early (e.g., before imaging, or some who refused frequent CT scans), so as to conduct appropriate clinical treatment of CPFE.

The nomogram provides a visualization of the regression equation, which has been accepted as a reliable tool to create a simple intuitive graph of a statistical predictive model that quantifies the risk of a clinical event [15]. In this work, we performed a retrospective study to create an easy-to-use risk assessment nomogram model integrating multiple clinical risk factors for predicting the presence of CPFE to support clinicians in their treatment recommendations.

\section{Methods}

\section{Patient participants}

This retrospective study involved 85 patients with CPFE and 128 patients with IPF during the period between January 2015 to January 2020, from Beijing Hospital. Diagnosis of IPF was made according to an official ATS/ ERS/JRS/ALAT guideline [16]: subpleural, basal, predominantly reticular abnormality or honeycombing, with or without traction bronchiectasis, and the absence of an inconsistent UIP pattern. CPFE was defined according to Cottin et al's definitions [5], namely the presence of classic features of centrilobular and/or paraseptal emphysemas $(\geq 10 \%)$ in the upper lobes and pulmonary fibrosis (mainly IPF/UIP) in the lower lobes radiographically. Patients with other specific types of ILD, such as, pneumoconiosis, hypersensitivity pneumonitis, sarcoidosis, pulmonary Langerhans cell histiocytosis, lymphangioleiomyomatosis or eosinophilic pneumonias were excluded. The study was approved by Ethics Committee of Beijing Hospital (2020BJYYEC-053-02). Written informed consent was obtained from all participants.

\section{Data collection}

The following demographic and clinical data were extracted from electronic medical records at the time of the initial high-resolution computed tomography (HRCT) of the chest study: population characteristics (age, gender, body mass index (BMI), smoking history, thoracic operation history, allergies (drug allergy, with or without food allergy and hay fever), and occupational dust exposure), comorbidities (hypertension, reflux esophagitis, coronary disease, osteoporosis, stroke, and tumor), pulmonary function tests (RV, RV\%pred, VC, VC\%pred, VA, VA\%pred, TLC, TLC\%pred, FVC, FVC\%pred, FEV1/FVC\%, FEV1, FEV1\%pred, DLCO, $\mathrm{DLCO} / \mathrm{VA}$, and DLCO/VA\%pred), data required for the Charlson Comorbidity Index (CCI) [17], and composite physiologic index (CPI) [18]. Spirometric data were collected using MasterScreen ${ }^{\mathrm{TM}}$ spirometer (CareFusion, Germany, $234 \mathrm{Gmbh}$ ) and the European Community of Coal and Steel (ECCS) predicted equations were used to calculate predicted values [19]. These data were verified by two experienced physicians independently.

\section{Statistical analysis}

Continuous variables were described using median and interquartile range (IQR). Categorical variables were described as number (\%). Non-normal distributed continuous data were compared using Mann-Whitney-U test. Categorical data were compared using $\mathrm{X}^{2}$ test or the Fisher exact test. Correlations between variables were analyzed using the Spearman's rank correlation. Correlation strength was selected by an absolute correlation 
$(|\mathrm{r}|>0.2)$ and the selected correlation was plotted as an undirected network graph. Multivariable logistic regression analysis was implemented to identify the powerful combination of significant factors which were utilized to build a prediction model and a nomogram was used to visualize the model.

The nomogram was subjected to 1000 bootstrap resamples for internal validation and the performance was assessed by discrimination and calibration [20]. Harrell's concordance index (C-index), the area under the receiver operating characteristic curve (AUC) was used to verify the discrimination of the model, while the calibration plot was used to graphically evaluate the calibration of the nomogram. The C-index ranges from 0.5 to 1.0 , with 0.5 indicating random chance and 1.0 demonstrating perfect discrimination. In general, an AUC $>0.75$ was considered to be relatively good discrimination. Moreover, the Hosmer-Lemeshow $(\mathrm{H}-\mathrm{L})$ test was used to examine how well the percentage of the observed probability matched the percentage of predicted probability over deciles of predicted risk.

The statistical analyses were performed with IBM SPSS 25.0 and R 3.4.3 with the rms statistical packages for all the analyses. All tests were 2 -sides, and a $\mathrm{P}$ value $<0.05$ was considered statistically significant.

\section{Results}

\section{Population characteristics}

Of the 300 patients initially retrieved from the medical record system, 85 CPFE patients and 128 IPF patients were eventually involved for analysis (Fig. 1). Table 1 summarized the details of baseline characteristics of enrolled patients. Compared to the IPF group, the proportion of patients with male $(91.8 \%$ vs. $55.5 \%$, $P=0.000)$, smoking $(88.1 \%$ vs. $46.3 \%, P=0.000)$ and allergies $(24.4 \%$ vs. $11.5 \%, P=0.000)$ were significantly

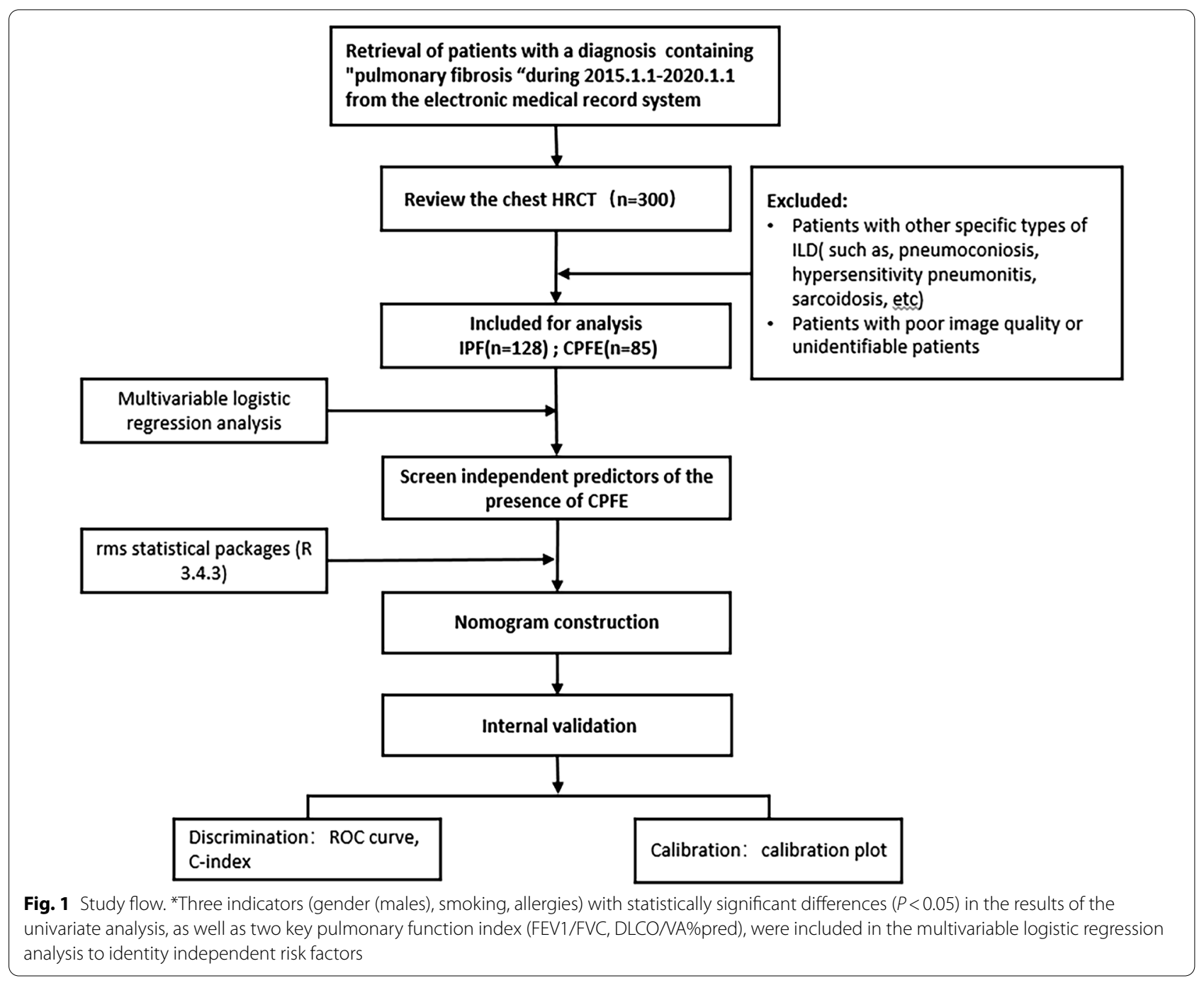


Table 1 Demographic and baseline characteristics of enrolled patients

\begin{tabular}{|c|c|c|c|c|}
\hline & All patients $(\mathrm{N}=213)$ & CPFE $(\mathrm{N}=85)$ & IPF $(N=128)$ & $P$ value \\
\hline \multicolumn{5}{|l|}{ Demographic } \\
\hline Age, median (IQR), yrs & $75(65-81)$ & $75(66-81)$ & $75(64-82)$ & 0.72 \\
\hline Gender, Male, n (\%) & $149(70.0)$ & $78(91.8)$ & $71(55.5)$ & $0.000^{*}$ \\
\hline BMI $\left(\mathrm{kg} / \mathrm{m}^{2}\right)$ & $24.9(22.3-26.7)$ & $24.7(21.1-26.6)$ & $25.0(22.6-27.4)$ & 0.32 \\
\hline $\mathrm{BMI} \geq 24, \mathrm{n}(\%)$ & $29(17.1)$ & $11(15.5)$ & $18(18.2)$ & 0.65 \\
\hline Smoking, n (\%) & $131(63.3)$ & $74(88.1)$ & $57(46.3)$ & $0.000^{*}$ \\
\hline Thoracic operation history, n (\%) & $6(2.9)$ & $1(1.2)$ & $5(4.1)$ & 0.233 \\
\hline Allergies n (\%) & $34(16.7)$ & $20(24.4)$ & $14(11.5)$ & $0.015^{*}$ \\
\hline Occupational dust exposure, $\mathrm{n}(\%)$ & $45(22.2)$ & $16(19.8)$ & $29(23.8)$ & 0.5 \\
\hline \multicolumn{5}{|l|}{ Comorbidities, n (\%) } \\
\hline Hypertension & $85(41.9)$ & $33(41.3)$ & $52(42.3)$ & 0.885 \\
\hline Reflux esophagitis & $39(18.9)$ & $17(20.2)$ & $22(18.0)$ & 0.691 \\
\hline Coronary disease & 65 (31.9) & $27(33.3)$ & $38(30.9)$ & 0.715 \\
\hline Diabetes & $50(24.4)$ & $19(23.5)$ & $31(25.0)$ & 0.801 \\
\hline Osteoporosis & $22(10.8)$ & $7(8.5)$ & $15(12.3)$ & 0.396 \\
\hline Chronic kidney diseases & $15(7.4)$ & $4(4.9)$ & $11(9.1)$ & 0.270 \\
\hline Stroke & $33(16.0)$ & $14(17.3)$ & $19(15.2)$ & 0.690 \\
\hline Tumor & $39(18.3)$ & $18(21.1)$ & $21(16.4)$ & 0.378 \\
\hline $\mathrm{CCl}$, median (IQR) & $1(0-2)$ & $1(0-2)$ & $1(0-2)$ & 0.80 \\
\hline CPI, median (IQR) & $39.4(30.2-52.3)$ & $38.9(26.9-53.9)$ & $40.8(31.9-50.0)$ & 0.73 \\
\hline
\end{tabular}

${ }^{*} P<0.05$

higher in the CPFE group. No statistical difference was found in terms of age, BMI, most personal history and comorbidities between two groups $(P>0.05)$. In addition, according to the CCI and CPI assessment, the differences of indexes were not statistically significant $(P>0.05)$ (Table 1$)$.

\section{Comparison and correlation network analysis of pulmonary function indexes}

Patients were admitted primarily for identifying the causes and confirming diagnosis, and pulmonary function was measured as physically permissible for medical purpose. FEV1/FVC\% and DLCO/VA in CPFE group were significantly lower than those in IPF group $(P<0.05)$. Conversely, RV, RV\%pred, VC, VC\%pred, VA, TLC, TLC\%pred, FVC, FVC\%pred and FEV1 were significantly higher than those in IPF group $(P<0.05)$ (Table 2). Moreover, the correlation analysis between each of the two indexes of pulmonary function was shown as an undirected network graph (Fig. 2). The line's thickness is proportional to the absolute value of correlation strength. DLCO positively correlated with VA\% $(r=0.470, P=0.000), \mathrm{RV} \%(r=0.332, P=0.005)$ and TLC\% $\left(r=0.511_{2} P=0.000\right)$ in IPF group but no correlation was observed in CPFE group.

\section{Analysis of risk factors for CPFE}

The variables univariately associated with $\mathrm{CPFE}$ at $P<0.05$ level, including gender (male), smoking, allergies and key pulmonary function index (FEV1/FVC\%, DLCO/ VA\%pred), were entered into the multivariable logistic regression analysis. As shown in the Table 3, the final multivariate logistic regression analysis yielded five statistically significant independent factors: gender (male) $(P=0.025)$, smoking $(P=0.044)$, allergies $(P=0.006)$, FEV1/FVC\% $(P=0.003)$, DLCO/VA\% pred $(P=0.017)$.

\section{Nomogram construction and validation}

The nomogram was constructed based on five independent variables (gender (male), smoking, allergies, FEV1/ FVC\%, and DLCO/VA\% pred) (Fig. 3). Each variable was scored on a scale, and the range of the total points was 0-240. Points for gender (male), smoking, allergies, were 27.6, 23.0 and 28.4 respectively, and the specific points for $\mathrm{FEV} 1 / \mathrm{FVC} \%$ and DLCO/VA\% pred are determined by drawing a line straight upward to the point axis based on the values of the continuous variables. Finally, the total points on the risk axis represents the probability of CPFE.

Performance of this nomogram was assessed by C-index, AUC and calibration plots. The C-index of the nomogram was 0.863 (95\% CI 0.795-0.931) and the AUC was 0.839 (95\% CI 0.764-0.913), both indicating stable 
Table 2 Comparison of pulmonary function indexes among groups

\begin{tabular}{|c|c|c|c|c|}
\hline Pulmonary function indexes (IQR) & All patients $(\mathrm{N}=213)$ & CPFE $(\mathrm{N}=85)$ & IPF $(N=128)$ & $P$ value \\
\hline $\mathrm{RV}(\mathrm{L})$ & $1.9(1.6-2.3)$ & $2.1(1.8-2.5)$ & $1.7(1.4-2.1)$ & $0.000^{*}$ \\
\hline RV\%pred & $80.3(69.8-93.5)$ & $82.2(74.5-99.0)$ & $79.1(65.2-90.5)$ & $0.042^{*}$ \\
\hline VC (L) & $2.5(1.9-3.0)$ & $2.9(2.3-3.3)$ & $2.1(1.6-2.7)$ & $0.000^{*}$ \\
\hline VC\%pred & $76.3(66.7-87.2)$ & $81(70.1-92.0)$ & $72.8(64.2-85.1)$ & $0.028^{*}$ \\
\hline VA $(L)$ & $4.1(3.2-5.0)$ & $4.8(3.9-5.3)$ & $3.9(2.8-4.7)$ & $0.000^{*}$ \\
\hline VA\%pred & $72.3(63.1-82.3)$ & $76.4(65.5-83.3)$ & $70.0(59.8-79.1)$ & 0.118 \\
\hline $\operatorname{TLC}(\mathrm{L})$ & $4.3(3.4-5.1)$ & $5(4.1-5.5)$ & $3.9(3.1-4.9)$ & $0.000^{*}$ \\
\hline TLC\%pred & $73.3(65.1-80.6)$ & $77.8(69.3-84.5)$ & $70.2(61.0-77.8)$ & $0.002^{*}$ \\
\hline $\mathrm{FVC}(\mathrm{L})$ & $2.4(1.8-3.0)$ & $2.9(2.3-3.2)$ & $2.1(1.6-2.7)$ & $0.000^{*}$ \\
\hline FVC\%pred & $78.1(67.8-88.4)$ & $81.5(71.4-93.0)$ & $74.4(65.5-83.1)$ & $0.013^{*}$ \\
\hline FEV1 (L) & $1.9(1.4-2.3)$ & $2.1(1.7-2.5)$ & $1.7(1.3-2.2)$ & $0.001^{*}$ \\
\hline FEV1\%pred & $79.0(66.9-93.6)$ & $79.2(69.3-91.1)$ & $79.0(65-94.8)$ & 0.624 \\
\hline FEV1/FVC (\%) & $82.1(76.0-87.0)$ & $79.2(71.5-84.1)$ & $84.4(78.6-88.5)$ & $0.000^{*}$ \\
\hline DLCO/NA (mol/min/kPa/L) & $1.2(0.8-1.5)$ & $1.1(0.8-1.4)$ & $1.3(1.0-1.5)$ & $0.021^{*}$ \\
\hline DLCO/NA\%pred & 78.05 (63.35-97.75) & $76.3(59.5-94.1)$ & $86.3(69.6-98.5)$ & 0.066 \\
\hline
\end{tabular}

${ }^{*} P<0.05$

\section{IPF}

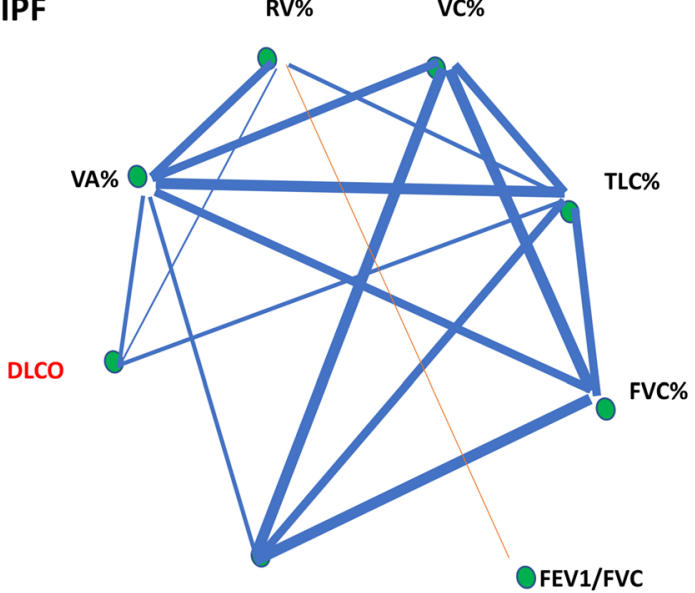

FEV1\%

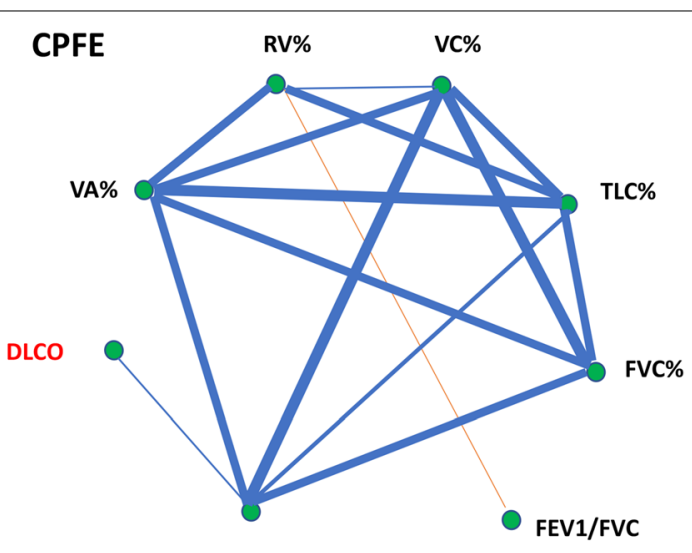

FEV1\%

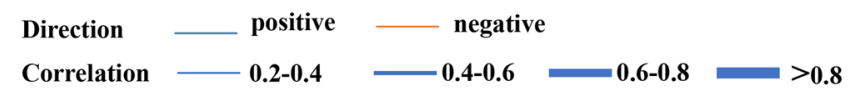

Fig. 2 Correlation networks for pulmonary function index among groups. Networks showed different profiles of correlations in CPFE and IPF patients. The width of the edge is proportional to the absolute value of correlation strength $(|r|)$. Edges were shown only when $|r|>0.2$. A blue edge indicates a positive correlation, and an orange edge indicates a negative correlation

Table 3 Multivariable logistic regression analysis results for presence of CPFE

\begin{tabular}{lllllll}
\hline Variables & B & SE & Waldx2 & P & OR & 95\% Cl \\
\hline Gender (males) & 1.767 & 0.788 & 5.021 & $0.025^{*}$ & 5.852 & $1.248-27.439$ \\
Smoking & 1.471 & 0.732 & 4.042 & $0.044^{*}$ & 4.353 & $1.038-18.262$ \\
Allergies & 1.824 & 0.662 & 7.585 & $0.006^{*}$ & 6.196 & $1.692-22.687$ \\
FEV1/FVC\% & -0.079 & 0.027 & 8.851 & $0.003^{*}$ & 0.924 & $0.877-0.973$ \\
DLCONA\%pred & -0.024 & 0.010 & 5.712 & $0.017^{*}$ & 0.976 & $0.957-0.996$ \\
\hline
\end{tabular}




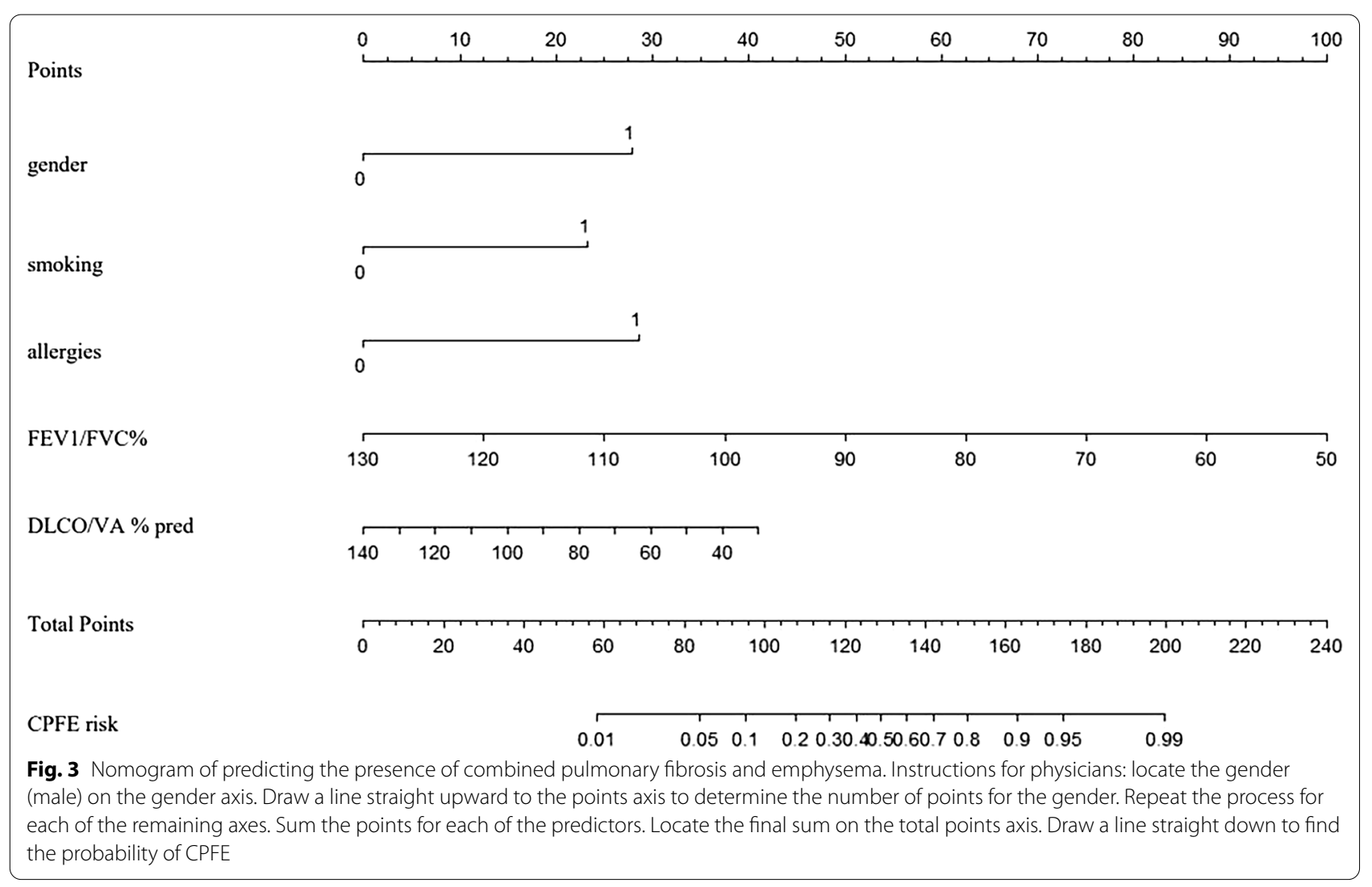

and favorable performance of the model. Moreover, the calibration plot showed good concordance of incidence of CPFE between nomogram prediction and actual observation (Hosmer-Lemeshow test: $P=0.307$ ) (Fig. 4).

\section{Discussion}

CPFE is considered as a not fully recognized syndrome characterized by chronic, progressive disease with worsening respiratory symptoms, reduced lung function and poor prognosis [5]. The analysis of risk factors has guiding significance for the early recognition, clinical diagnosis and appropriate treatment. Here, this study describes the clinical characteristics and incorporates multiple clinical variables into a user-friendly nomogram for predicting the presence of CPFE.

With the presence of fibrosis and emphysema concomitantly, pulmonary function tests of CPFE patients are characterized by the preservation of lung volumes and markedly impaired carbon monoxide diffusing capacity, rather than the simple coexistence [21]. The relatively normal lung volumes in CPFE usually result from the counterbalancing effects of the restrictive disorder of fibrosis and the hyperinflation of emphysema [22], meanwhile, the presence of these two factors leading to severe reduction in the amounts of functional alveolar-capillary units [23]. Our results indicated that CPFE patients showed significantly higher lung volume (RV, VC, and TLC) and ventilation indicators (VA, FVC, and FEV1), and DLCO/VA were much more decreased, consistent with previous studies. Moreover, positive correlation was observed between DLCO and VA\%, RV\%, TLC\% in patients with IPF but not in patients with CPFE, which remind us more clinical attention on the variation consistency of lung volume, ventilation and diffusion function indicators.

Most patients with CPFE are males, and they are either current or ex-smokers $[24,25]$. Current study demonstrated that smoking has been considered as a risk factor for the development of CPFE [26]. The results of this study came to the same conclusion. The mechanism behind this could also be due to a sequence of events that first cause bronchial inflammation, small airway stenosis and alveolar rupture leading to emphysema; and then additionally stimulate the epithelial mesenchymal transition (EMT) to promote the differentiation of fibroblasts into myofibroblasts [25]. In addition, late-onset increased gastroesophageal reflux (GER) triggered by smoking may also aggravate the fibrotic changes [27].

The higher proportion of patients with allergies in the CPFE group indicated that immune mediators (mast 


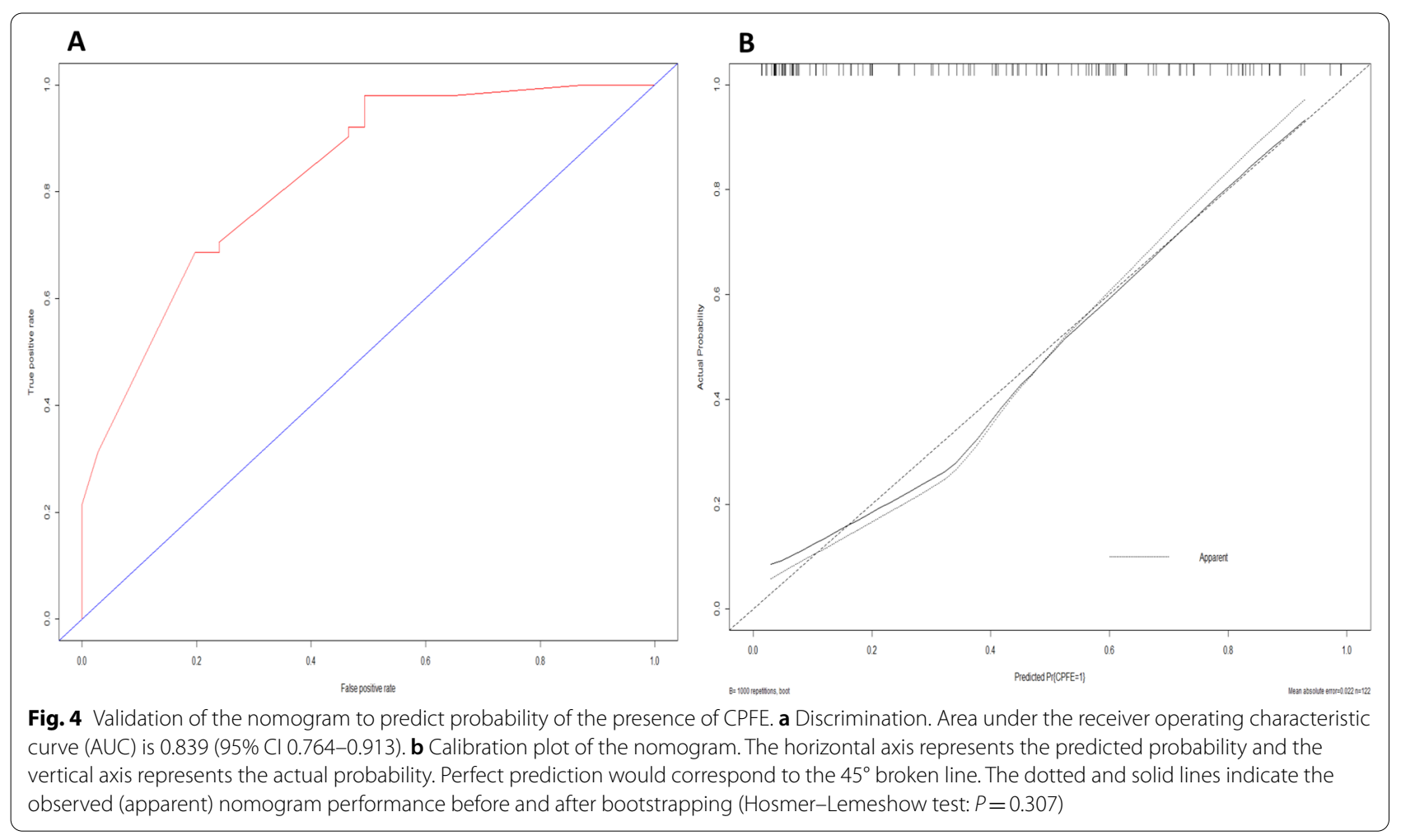

cells, basophils, eosinophils, cytokines, chemokines, etc.) may be associated with the development of disease. Several studies have demonstrated that air contamination is closely related to emphysema and pulmonary fibrosis [28]. Allergy-prone patients who have more abundant and expressed IgE and FceR receptors [29] may experience more significant inflammation and immune responses when exposed to airborne antigens. Furthermore, TGF- $\beta 1$, for example, is known to play an major role in the differentiation of fibroblasts into myofibroblasts [30] and eosinophil-derived IL-13 is closely associated with emphysema [31]. It can be speculated that immune impairment in CPFE patients may be more pronounced due to the superimposed effect of immune damage in pulmonary fibrosis and emphysema.

Smoking is undoubtedly a main factor, but not all CPFE patients in this study had a history of smoking $(88 \%)$. On the one hand, patients with second-hand smoke who are not easily defined may be ignored; on the other hand, it is currently believed that multiple factors are involved in the development of CPFE. Besides inflammation, gene-mediated alveolar damage processes may also lead to CPFE [29]. Oxidative stress and accelerated lung aging with telomere shortening has been proposed as a possible mechanism related to CPFE pathogenesis as well [32]. Another theory suggests that fibrosis occurs predominantly at the base of the lung and can cause local lobe contraction, with progressive compensatory emphysematous changes in the upper lobes of the lung affected by tensile forces [33], consistent with the classical imaging features of CPFE. In short, further studies are needed to shed light on the pathogenesis of CPFE.

In our study, we use multivariable logistic regression analysis to identify significant factors associated with CPFE. Consequently, gender (male), smoking, allergies, FEV1/FVC\%, DLCO/VA\% pred were identified and used to develop the prognostic nomogram. This nomogram demonstrated good discrimination as assessed by the C-index, AUC value and calibration plot indicating good performance. Nomogram models are used to assess the risks associated with $\mathrm{CPFE}$ and they also provide a reference for the clinical management.

Although our study lies in the intuitive characteristics of the disease based on the real-world data and the relatively complete information, which can ensure the accuracy of the model, there are still some limitations. First, the data for the nomogram were retrospectively derived from a single center and may suffer from selection bias. Second, only internal verification was performed and the results may overestimate the effectiveness of the model. Thus, external verification will be optimal for further investigation. 
In conclusion, our nomogram incorporating several important clinical variables into the estimate of the risk of CPFE may serve as a potential tool to help inform decision-making by physicians and patients.

\author{
Abbreviations \\ CPFE: Combined pulmonary fibrosis and emphysema; IPF: Idiopathic pulmo- \\ nary fibrosis; ILD: Interstitial lung diseases; UIP: Usual interstitial pneumonia; \\ BMI: Body mass index; CCl: Charlson Comorbidity Index; CPI: Composite \\ physiologic index; C-index: Concordance index; AUC: Areas under the receiver \\ operating characteristic curve; EMT: Epithelial mesenchymal transition; GER: \\ Gastroesophageal reflux.
}

\section{Acknowledgements}

Not applicable.

\section{Authors' contributions}

$X Y, J J$ and $X X$ contributed to the design of the study; $X Y$ and JJ were involved in data collection and analysis; $X Y$ wrote the initial draft of the manuscript, and the remaining authors were involved in revising the manuscript. All authors read and approved the final manuscript.

\section{Funding}

This project was supported by project Grant BJ-2019-152 from Beijing Hospital.

\section{Availability of data and materials}

The data that support the findings of this study are available from the corresponding author upon reasonable request.

\section{Declarations}

\section{Ethics approval and consent to participate}

The study protocol was approved by the Institute Ethics Committee of Beijing Hospital (2020BJYYEC-053-02). The study protocol conformed to the ethical guidelines of the 1975 Helsinki Declaration. Written informed consent was obtained from all patients.

\section{Consent for publication}

Not applicable.

\section{Competing interests}

The authors declare no competing interests.

\begin{abstract}
Author details
${ }^{1}$ The Key Laboratory of Geriatrics, Beijing Institute of Geriatrics, Beijing Hospital, National Center of Gerontology, National Health Commission, Institute of Geriatric Medicine, Chinese Academy of Medical Sciences, No. 1 DaHua Road, Dong Dan, Beijing 100730, People's Republic of China. ${ }^{2}$ Department of Pulmonary and Critical Care Medicine, Beijing Hospital, National Center of Gerontology, Institute of Geriatric Medicine, Chinese Academy of Medical Sciences, Beijing, People's Republic of China.
\end{abstract}

Received: 3 August 2021 Accepted: 1 November 2021 Published online: 07 November 2021

\section{References}

1. Mikolasch TA, Garthwaite HS, Porter JC. Update in diagnosis and management of interstitial lung disease. Clin Med (Lond). 2017;17:146-53.

2. Caminati A, Lonati C, Cassandro R, Elia D, Pelosi G, Torre O, Zompatori M, Uslenghi E, Harari S. Comorbidities in idiopathic pulmonary fibrosis: an underestimated issue. Eur Respir Rev. 2019;28:66.

3. Mouronte-Roibás C, Leiro-Fernández V, Fernández-Villar A, Botana-Rial M, Ramos-Hernández C, Ruano-Ravina A. COPD, emphysema and the onset of lung cancer. A systematic review. Cancer Lett. 2016;382:240-4.
4. Amariei DE, Dodia N, Deepak J, Hines SE, Galvin JR, Atamas SP, Todd NW. Combined pulmonary fibrosis and emphysema: pulmonary function testing and a pathophysiology perspective. Medicina. 2019;55:66.

5. Cottin V, Nunes H, Brillet PY, Delaval P, Devouassoux G, Tillie-Leblond I, Israel-Biet D, Court-Fortune I, Valeyre D, Cordier JF. Combined pulmonary fibrosis and emphysema: a distinct underrecognised entity. Eur Respir J. 2005;26:586-93.

6. Kitaguchi Y, Fujimoto K, Hayashi R, Hanaoka M, Honda T, Kubo K. Annual changes in pulmonary function in combined pulmonary fibrosis and emphysema: over a 5-year follow-up. Respir Med. 2013;107:1986-92.

7. Jankowich MD, Rounds S. Combined pulmonary fibrosis and emphysema alters physiology but has similar mortality to pulmonary fibrosis without emphysema. Lung. 2010;188:365-73.

8. Mejía M, Carrillo G, Rojas-Serrano J, Estrada A, Suárez T, Alonso D, Barrientos E, Gaxiola M, Navarro C, Selman M. Idiopathic pulmonary fibrosis and emphysema: decreased survival associated with severe pulmonary arterial hypertension. Chest. 2009;136:10-5.

9. Kurashima K, Takayanagi N, Tsuchiya N, Kanauchi T, Ueda M, Hoshi T, Miyahara Y, Sugita Y. The effect of emphysema on lung function and survival in patients with idiopathic pulmonary fibrosis. Respirology. 2010;15:843-8.

10. Cottin V, Le Pavec J, Prévot G, Mal H, Humbert M, Simonneau G, Cordier JF. Pulmonary hypertension in patients with combined pulmonary fibrosis and emphysema syndrome. Eur Respir J. 2010;35:105-11.

11. Koo HJ, Do KH, Lee JB, Alblushi S, Lee SM. Lung cancer in combined pulmonary fibrosis and emphysema: a systematic review and meta-analysis. PLOS ONE. 2016;1 :e0161437.

12. Zantah M, Dotan Y, Dass C, Zhao H, Marchetti N, Criner GJ. Acute exacerbations of COPD versus IPF in patients with combined pulmonary fibrosis and emphysema. Respir Res. 2020;21:164.

13. Hage R, Gautschi F, Steinack C, Schuurmans MM. Combined pulmonary fibrosis and emphysema (CPFE) clinical features and management. Int $J$ Chron Obstruct Pulmon Dis. 2021;16:167-77.

14. Bolaki M, Antoniou KM. Combined pulmonary fibrosis and emphysema. Semin Respir Crit Care Med. 2020;41:177-83.

15. lasonos A, Schrag D, Raj GV, Panageas KS. How to build and interpret a nomogram for cancer prognosis. J Clin Oncol. 2008;26:1364-70.

16. Raghu G, Remy-Jardin M, Myers JL, Richeldi L, Ryerson CJ, Lederer DJ, Behr J, Cottin V, Danoff SK, Morell F, et al. Diagnosis of idiopathic pulmonary fibrosis. An official ATS/ERS/JRS/ALAT clinical practice guideline. Am J Respir Crit Care Med. 2018;198:e44-68.

17. Charlson ME, Pompei P, Ales KL, Mackenzie CR. A new method of classifying prognostic comorbidity in longitudinal studies: development and validation. J Chronic Dis. 1987;40:373-83.

18. Wells AU, Desai SR, Rubens MB, Goh NS, Cramer D, Nicholson AG, Colby TV, du Bois RM, Hansell DM. Idiopathic pulmonary fibrosis: a composite physiologic index derived from disease extent observed by computed tomography. Am J Respir Crit Care Med. 2003;167:962-9.

19. Quanjer PH, Tammeling GJ, Cotes JE, Pedersen OF, Peslin R, Yernault JC. Lung volumes and forced ventilatory flows. Report working party standardization of lung function tests, European Community for steel and coal. Official statement of the European Respiratory Society. Eur Respir J Suppl. 1993;16:5-40.

20. Harrell FE Jr, Lee KL, Mark DB. Multivariable prognostic models: issues in developing models, evaluating assumptions and adequacy, and measuring and reducing errors. Stat Med. 1996;15:361-87.

21. Jankowich MD, Rounds SIS. Combined pulmonary fibrosis and emphysema syndrome: a review. Chest. 2012;141:222-31.

22. Kitaguchi Y, Fujimoto K, Hanaoka M, Honda T, Hotta J, Hirayama J. Pulmonary function impairment in patients with combined pulmonary fibrosis and emphysema with and without airflow obstruction. Int J Chron Obstruct Pulmon Dis. 2014;9:805-11.

23. Mura M, Zompatori M, Pacilli AM, Fasano L, Schiavina M, Fabbri M. The presence of emphysema further impairs physiologic function in patients with idiopathic pulmonary fibrosis. Respir Care. 2006;51:257-65.

24. Malli F, Papakosta D, Antoniou K, Dimadi M, Polychronopoulos V, Malagari K, Oikonomou A, Bouros DE, Daniil Z. Combined pulmonary fibrosis and emphysema characteristics in a Greek cohort. ERJ Open Res. 2019;5:66.

25. Zhang L, Zhang C, Dong F, Song Q, Chi F, Liu L, Wang Y, Che C. Combined pulmonary fibrosis and emphysema: a retrospective analysis of clinical characteristics, treatment and prognosis. BMC Pulm Med. 2016;16:137. 
26. Sauleda J, Núñez B, Sala E, Soriano JB. Idiopathic pulmonary fibrosis: epidemiology, natural history. Phenotypes Med Sci. 2018;6:66.

27. Bédard Méthot D, Leblanc É, Lacasse Y. Meta-analysis of gastroesophageal reflux disease and idiopathic pulmonary fibrosis. Chest. 2019;155:33-43.

28. Sack C, Vedal S, Sheppard L, Raghu G, Barr RG, Podolanczuk A, Doney B, Hoffman EA, Gassett A, Hinckley-Stukovsky K, et al. Air pollution and subclinical interstitial lung disease: the Multi-Ethnic Study of Atherosclerosis (MESA) air-lung study. Eur Respir J. 2017;50:66.

29. Simon D. Recent advances in clinical allergy and immunology 2019. Int Arch Allergy Immunol. 2019;180:291-305.

30. Ishikawa G, Liu A, Herzog EL. Evolving perspectives on innate immune mechanisms of IPF. Front Mol Biosci. 2021;8:676-569.
31. Doyle AD, Mukherjee M, LeSuer WE, Bittner TB, Pasha SM, Frere JJ, Neely $J$, Kloeber JA, Shim KP, Ochkur SI, et al. Eosinophil-derived IL-13 promotes emphysema. Eur Respir J. 2019;53:66.

32. Cronkhite JT, Xing C, Raghu G, Chin KM, Torres F, Rosenblatt RL, Garcia CK. Telomere shortening in familial and sporadic pulmonary fibrosis. Am J Respir Crit Care Med. 2008;178:729-37.

33. Hiwatari N, Shimura S, Takishima T. Pulmonary emphysema followed by pulmonary fibrosis of undetermined cause. Respiration. 1993;60:354-8.

\section{Publisher's Note}

Springer Nature remains neutral with regard to jurisdictional claims in published maps and institutional affiliations.
Ready to submit your research? Choose BMC and benefit from:

- fast, convenient online submission

- thorough peer review by experienced researchers in your field

- rapid publication on acceptance

- support for research data, including large and complex data types

- gold Open Access which fosters wider collaboration and increased citations

- maximum visibility for your research: over $100 \mathrm{M}$ website views per year

At BMC, research is always in progress.

Learn more biomedcentral.com/submissions 